

\title{
Inflammatory Biomarkers Predictive of Metabolic Syndrome in a Nigerian Population: A Case-Control Study Adejumo EN ${ }^{1 *}$, Adejumo $\mathrm{AO}^{2}$, Ogundahunsi $\mathrm{OA}^{3}$
}

${ }^{1}$ Department of Medical Laboratory Science, Babcock University, Ilishan-Remo, Ogun State, Nigeria 2Department of Community Health and Primary Health Care, Lagos State University Teaching Hospital, Ikeja, Lagos, Nigeria

${ }^{3}$ Department of Chemical Pathology, Olabisi Onabanjo University, Sagamu, Ogun State, Nigeria

*Correspondence: Dr EN Adejumo, Department of Medical Laboratory Science, Babcock University, Ilishan-

Remo, Ogun State Nigeria. E-mail: adejumoe@babcock.edu.ng;

ORCID - https://orcid.org/0000-0003-4260-5326.

\begin{abstract}
Background: Inflammation is linked to the aetiopathogenesis of Metabolic syndrome (MetS).

Objective: To assess the ability of high sensitivity C-Reactive Protein (hs-CRP), Tumour Necrosis Factor-alpha (TNFa) and Interleukin-6 (IL-6) to predict MetS.

Methods: A case-control study involving 123 subjects with MetS (cases) and age-matched 123 subjects. without MetS (controls) was conducted. The levels of TNFa, IL-6, and hs-CRP between independent groups were compared. The Receiver Operative Characteristic Curve was used to assess the ability of inflammatory markers to discriminately identify MetS.

Results: The mean age of the case and control groups was $49.9 \pm 0.9$ years and $48.1 \pm 1.1$ years $(p=0.274)$ respectively. The median levels of TNFa, IL-6 and hS-CRP were significantly higher among the cases than the control group in both genders ( $p<0.001)$. There was a significant increase in the serum values of the markers with increasing components of MetS ( $p$ <.001). The Area Under the Curve of TNFa, IL-6 and hs-CRP was > 0.9 in both males and females.

Conclusion: TNFa, IL-6, and hs-CRP identified MetS. There is a need for further studies to determine the inflammatory marker most predictive of MetS.
\end{abstract}

Keywords: Inflammatory markers, Interleukin-6, Metabolic syndrome, Tumour Necrosis Factor, Nigeria

\section{Introduction}

Globally, Metabolic syndrome (MetS) is of great concern because of its complexities, public health, clinical and socioeconomic implications. MetS is a combination of biochemical and anthropometric abnormalities which directly increase the risk of cardio-metabolic diseases. [1] Some sets of convergent and divergent diagnostic criteria with varying principal elements, such as obesity, hypertension, abnormal glucose and lipid metabolism, have been used to define the syndrome. [2]

The exact pathophysiology of MetS is still unclear; some hypotheses suggest that 
inflammation is central in the aetiology of MetS. [3] Biomarkers are useful in clinical practice to monitor the management of pathological disorders with no overt or measurable physiological or anatomical abnormalities; they have also been used to estimate the risk of infection for a certain population. ${ }^{4]}$ Studies have also shown that inflammatory markers are accentuated in patients with MetS and this has improved the prospects of the diagnostic criteria of cardio-metabolic risk factors. [5] Inflammatory markers such as Interleukin-6 (IL- 6), Tumor Necrotic Factor-alpha (TNFa), C-Reactive Protein (CRP), leptin, adiponectin, ghrelin, uric acid, plasminogen activator inhibitor, Interleukin-10, oxidized Low-Density-Lipoproteins and Paraoxonase-1 have been linked with MetS. [6-13] It has been suggested that a group of biomarkers, rather than a single biomarker, may aid the diagnosis of MetS better because of their complex and interrelated roles and pathways. [14]

The association of inflammatory markers (CRP, TNFa and IL-6) with MetS and its components have been reported in Nigerian studies [15,16] While a panel of biomarkers may be useful in the diagnosis of MetS, it may not be helpful in resource-poor settings. Therefore, there is a need to assess the inflammatory biomarkers most predictive of MetS in a resource-limited setting. This study assessed the ability of hs-CRP, TNFa and IL-6 to predict MetS.

\section{Methods}

\section{Study design}

A case-control study of 123 adults with MetS (cases) and age-matched 123 adults without MetS (control) was conducted as previously described. [17] The cases were adults with MetS (from the previous study) while the controls were participants without MetS (from the previous study). [17] Socio-demographic history, blood pressure and anthropometric measurements were documented in a structured questionnaire as earlier reported. [17] The details of the study location, selection of communities and sampling methods have been previously published. [17]

Sample size calculation and sampling technique: Using 1 as the ratio of cases to controls, the standard deviation of outcome variable of 9.5, power of $80 \%$, desired level of statistical significance of 1.96, mean value of CRP of the cases $(6.6 \mathrm{mg} / \mathrm{L})$ and control group $(3.1 \mathrm{mg} / \mathrm{L})$, [16] the minimum calculated sample size for the case-control study was 115 for each arm of the study.

Measurements of study variables

The measurements of blood pressure (BP) and waist circumference (WC) was done as previously described. [17]

After an overnight fast (10-12 hours duration), 10 $\mathrm{ml}$ of venous blood was drawn for lipid profile, fasting plasma glucose (FPG), TNF-a, IL 6, and hs-CRP estimation using appropriate specimen bottles such as fluoride oxalate, potassium ethylene diamine tetra-acetic acid and plain tubes respectively. After centrifugation, serum and plasma samples were stored at $-20^{\circ} \mathrm{C}$ until ready for analysis. Enzymatic methods were used to determine FPG, triglyceride (TRG) and HighDensity Lipoprotein Cholesterol (HDL-C) levels, while Enzyme-linked Immunosorbent Assay (DRG International Inc., USA) was employed in estimating serum levels of TNF-a, hs-CRP and IL 6. The accuracy and precision of the tests were assured using the quality control samples included in the reagents.

Definition of the criteria for metabolic syndrome Participants with three or more of the following criteria were classified as MetS cases: elevated TRG $\geq 150 \mathrm{mg} / \mathrm{dl}$, HDL-C $<40 \mathrm{mg} / \mathrm{dl}$ in males and $<50 \mathrm{mg} / \mathrm{dl}$ in females, systolic BP $\geq 130 \mathrm{~mm} \mathrm{Hg}$ or diastolic BP $\geq 85 \mathrm{~mm} \mathrm{Hg}, \mathrm{FPG} \geq 100 \mathrm{mg} / \mathrm{dl}$ and $W C \geq 94 \mathrm{~cm}$ in men or $\geq 80 \mathrm{~cm}$ in women. [18]

\section{Ethical consideration}


The Institutional Review Boards (IRB) of the Lagos State University Teaching Hospital and Babcock University granted the ethical approvals for the conduct of the study.

\section{Statistical analysis}

The IBM SPSS statistics version 22 was used for data analysis. Histogram plot and test for normality were conducted to determine the normality of the outcome variable data (TNFa, hs-CRP and IL- 6 levels). Mann Whitney U and Kruskal-Wallis tests were used to compare median of two or more than two independent groups respectively. Discrete variables were compared using Chi-Square test of independence. Pearson's correlation was used to determine the relationship between the values of inflammatory markers and the components of MetS. The Receiver Operating Characteristic (ROC) curve was used to assess the ability of the inflammatory markers to discriminately identify MetS. Statistical significance was defined by $p$ values less than 0.05 .

\section{Results}

The socio-demographic and anthropometric details of the cases and control are shown in Table I. The mean age of the control and case groups was $48.1 \pm 1.1$ years and $49.9 \pm 0.9$ years respectively $(p=0.274)$. There were more females among the cases than the control group $(77.2 \%$ vs $62.6 \%)(p=0.012)$.

Table II compared the median serum levels of inflammatory markers and the components of Met $S$ between the cases and controls. The median serum levels of TNFa, IL- 6, hs-CRP, triglyceride, FPG, WC, systolic and diastolic BP were higher among the cases than the controls $(p<0.001)$. The serum levels of TNFa, IL- 6, hS-CRP were higher also among the cases than the control groups in both males and females $(p<0.001)$ (Table III). In both sexes, the median serum levels of TNFa, IL-
6, and hs-CRP increased with the increasing number of components of MetS $(p<0.001)$ (Table IV).

The correlations of serum levels of TNFa, IL- 6, and hs-CRP with the components of MetS are shown in Table V. Serum levels of TNF-a, IL 6, and hs-CRP showed significant positive correlations with WC, FPG, TRG, systolic and diastolic blood pressure $(p<0.001)$ but negative correlations with HDL-C $(p<0.001)$.

Table VI illustrates the ability of serum levels of TNFa, IL- 6, and hs-CRP to discriminately identify MetS. Serum levels of TNFa, IL- 6, and hs-CRP had a large area under the curve (AUC) $(>0.9)$. However, the serum level of TNFa had the largest area under the curve AUC compared with IL- 6 and hs-CRP in both men and women.

\section{Discussion}

This study assessed the ability of serum levels of CRP, TNFa and IL-6 to discriminately identify MetS among adults. This study found that the serum levels of inflammatory markers IL-6, TNFa and hs-CRP were elevated among the cases compared with the controls and the levels were increased with the increasing number of the components of MetS in males and females. All the inflammatory markers studied (TNFa, IL- 6 and hS-CRP) had good and comparable ability to discriminately identify Mets (AUC >0.9) in both genders.

The exact pathogenesis of MetS is still poorly understood although experts believe that inflammatory pathways contribute largely to this disorder. [19] It has been hypothesized that oxidative stress, which is linked to inflammation, is thought to be responsible for the dysregulated secretion of adipokines and other inflammatory markers culminating in dyslipidaemia, hyperglycaemia and insulin resistance. [20] 
Table I: Socio-demographic characteristics of study participants

\begin{tabular}{|c|c|c|c|c|c|}
\hline \multirow{2}{*}{$\begin{array}{l}\text { Characteristics } \\
\text { Age group (Years }\end{array}$} & \multicolumn{2}{|c|}{$\begin{array}{l}\text { Control } \\
\text { n (\%) }\end{array}$} & \multirow[t]{2}{*}{$\begin{array}{c}\text { Case } \\
\text { n (\%) }\end{array}$} & \multirow[t]{2}{*}{ Chi-Square } & \multirow[t]{2}{*}{ p-value } \\
\hline & & & & & \\
\hline$<30$ & $5(4.1)$ & $0(0.0)$ & & 1.161 & 0.274 \\
\hline $30-39$ & $27(22.0)$ & $20(16.2)$ & & & \\
\hline $40-49$ & $34(27.6)$ & $44(35.8)$ & & & \\
\hline $50-59$ & $34(27.6)$ & $36(29.3)$ & & & \\
\hline$\geq 60$ & $23(18.7)$ & $23(18.7)$ & & & \\
\hline Mean $\pm S D$ & $48.1 \pm 1.1$ & $49.9 \pm 0.9$ & & & \\
\hline \multicolumn{6}{|l|}{ Gender } \\
\hline Male & $46(37.4)$ & $28(22.8)$ & & 6.262 & 0.012 \\
\hline Female & 77 (62.6) & 95 (77.2) & & & \\
\hline \multicolumn{6}{|l|}{ Marital Status } \\
\hline Married & $70(56.9)$ & $100(81.3)$ & & 17.14 & 0.000 \\
\hline Not married* & $53(43.1)$ & $23(18.7)$ & & & \\
\hline \multicolumn{6}{|c|}{ Education status } \\
\hline None & $15(12.2)$ & $14(11.4)$ & & 0.78 & 0.8541 \\
\hline Primary & $26(21.1)$ & $31(25.2)$ & & & \\
\hline Secondary & 45 (36.6) & 40 (32.6) & & & \\
\hline Tertiary & $37(30.1)$ & 38 (30.9) & & & \\
\hline \multicolumn{6}{|c|}{ Cigarette smoking } \\
\hline Yes & $18(14.6)$ & $10(8.1)$ & & 2.579 & 0.108 \\
\hline No & $105(85.4)$ & $113(91.9)$ & & & \\
\hline \multicolumn{6}{|l|}{ Alcohol intake } \\
\hline Yes & $29(23.6)$ & $25(20.3)$ & & 0.380 & 0.538 \\
\hline No & $94(76.4)$ & 98 (79.7) & & & \\
\hline \multicolumn{6}{|l|}{ Location } \\
\hline Urban & $52(42.3)$ & $68(55.3)$ & & 4.165 & 0.041 \\
\hline Rural & $71(57.7)$ & $55(44.7)$ & & & \\
\hline
\end{tabular}

SD - Standard deviation

*Not married includes single, divorced, separated and widow/widower

In this study, the participants with MetS had elevated serum levels of hs-CRP, IL-6 and TNFa levels compared to non-MetS participants in both genders similar to what was reported from another Nigerian centre, the United States and Thailand. [15, 21, 22] Contrary to our findings, the studies from Asia reported serum IL-6 levels to be reduced or not different among diabetic patients compared with healthy controls. [23, 24] The differences in the sample size, sampling method, gender distribution, divergent environmental and social settings may account for this variation.

This study reported that inflammatory markers increased with the increasing number of the components of MetS similar to other studies. The serum levels of IL-6, TNFa and hs-CRP were positively correlated with FPG, triglyceride, blood pressure but negatively correlated with HDLc in this study. 
Table II: Differences in the median serum levels of inflammatory markers and components of metabolic syndrome in cases (MetS) and controls (Non-MetS)

\begin{tabular}{|c|c|c|c|c|}
\hline Parameters & Controls $(n=123)$ & Cases $(n=123)$ & $U$ & $P$ \\
\hline & Median (IQR) & Median (IQR) & & \\
\hline TNF-a (pg/ml) & $4.0(2.0,5.0)$ & $10.0(8.0,10.0)$ & 12.85 & $<0.001$ \\
\hline IL-6 (pg/ml) & $6.4(5.3,7.4)$ & $14.0(11.10,17.2)$ & 13.04 & $<0.001$ \\
\hline Hs-CRP (mg/l) & $2.1(1.3,3.4)$ & $6.2(5.3,6.5)$ & 12.41 & $<0.001$ \\
\hline $\mathrm{WC}(\mathrm{cm})$ & $86.0(75.0,96.0)$ & $99.1(91.4,100.7)$ & 7.47 & $<0.001$ \\
\hline SBP (mmHg) & $120.0(110.0,135.0)$ & $140.0(130.0,158.0)$ & 7.37 & $<0.001$ \\
\hline DBP (mmHg) & $73.0(70.0,80.0)$ & $88.0(80.0,100.0)$ & 7.60 & $<0.001$ \\
\hline FPG (mg/dl) & $88.0(77.0,94.3)$ & $104.0(90.5,107.0)$ & 7.36 & $<0.001$ \\
\hline $\mathrm{TG}(\mathrm{mg} / \mathrm{dl})$ & $78.0(57.5,105.4)$ & $90.1(76.0,158.5)$ & 4.35 & $<0.001$ \\
\hline HDL-c (mg/dl) & $54.7(39.8,64.6)$ & $42.6(36.6,47.6)$ & 4.97 & $<0.001$ \\
\hline
\end{tabular}

IQR - Interquartile Range; U - Mann Whitney U Test

TNF-a - Tumour Necrotic Factor-alpha; IL-6- Interleukin-6; hs-CRP- high sensitivity C-Reactive Protein;

WC- Waist circumference; SBP- Systolic Blood Pressure; DBP - Diastolic Blood Pressure; FPG - Fasting Plasma Glucose; TG - Triglycerides; HDL-C- High-Density Lipoprotein Cholesterol

Table III: Gender differences in the serum levels of inflammatory markers among cases and controls

\begin{tabular}{lllll}
\hline Parameters & \multicolumn{1}{c}{ Case } & \multicolumn{1}{c}{ Control } & \\
\hline & Median (IQR) & $\frac{\text { Median (IQR) }}{\mathrm{n}=46}$ & $\mathrm{U}$ & $\boldsymbol{P}$ \\
Males & $\mathrm{n}=28$ & & \\
TNF-a $(\mathrm{pg} / \mathrm{ml})$ & $11(9.1,13.0)$ & $3.0(2.0,5.0)$ & 1.820 & $<0.001$ \\
IL-6 $(\mathrm{pg} / \mathrm{ml})$ & $14.3(11.4,16.1)$ & $6.0(4.2,7.4)$ & 0.097 & $<0.001$ \\
hs-CRP $(\mathrm{mg} / \mathrm{ml})$ & $6.1(5.3,6.4)$ & $2.1(1.2,3.6)$ & 0.846 & $<0.001$ \\
& & & & \\
Females & $\mathrm{n}=95$ & $\mathrm{n}=77$ & & \\
TNF-a $(\mathrm{pg} / \mathrm{ml})$ & $9.0(8.0,13.0)$ & $4.0(3.0,5.0)$ & 2.544 & $<0.001$ \\
IL-6 $(\mathrm{pg} / \mathrm{ml})$ & $13.9(10.3,17.3)$ & $6.6(5.5,7.5)$ & 2.206 & $<0.001$ \\
hs-CRP $(\mathrm{mg} / \mathrm{ml})$ & $6.2(5.3,6.7)$ & $2.2(1.3,3.4)$ & 0.238 & $<0.001$ \\
\hline
\end{tabular}

IQR - Interquartile Range U - Mann Whitney U test

TNF-a- Tumour Necrotic Factor-alpha; IL-6- Interleukin-6; hs-CRP- high sensitivity C-Reactive Protein

Table IV: Relationship between Inflammatory markers and increasing components of metabolic syndrome

\begin{tabular}{|c|c|c|c|c|c|c|}
\hline \multirow[t]{2}{*}{ Parameters } & \multicolumn{6}{|c|}{ Number of components } \\
\hline & 0 & 1 & 2 & 3 & $>3$ & $P$ \\
\hline & Median (IQR) & Median (IQR) & Median (IQR) & Median (IQR) & Median (IQR) & \\
\hline Males & $\mathrm{n}=10$ & $\mathrm{n}=52$ & $\mathrm{n}=48$ & $\mathrm{n}=74$ & $\mathrm{n}=49$ & \\
\hline TNF-a (pg/ml) & $2.0(2.0,2.0)$ & $2.0(2.0,3.0)$ & $5.0(4.0,5.0)$ & $11.0(8.5,12.0)$ & $11.0(9.5,13.0)$ & $<0.001$ \\
\hline IL-6 (pg/ml) & $5.4(41 ., 6.5)$ & $5.6(4.2,7.4)$ & $6.4(4.6,8.3)$ & $15.2(10.7,15.8)$ & $12.9(11.9,18.4)$ & $<0.001$ \\
\hline hs-CRP (mg/ml) & $1.0(0.7,2.0)$ & $1.6(1.2,3.2)$ & $4.0(2.7,5.1)$ & $6.2(4.5,6.4)$ & $5.9(5.6,6.4)$ & $<0.001$ \\
\hline Females & $\mathrm{n}=13$ & $\mathrm{n}=33$ & $\mathrm{n}=31$ & $\mathrm{n}=57$ & $\mathrm{n}=38$ & \\
\hline TNF-a $(\mathrm{pg} / \mathrm{ml})$ & $2.0(2.0,2.5)$ & $2.0(2.0,5.2)$ & $5.0(5.0,6.0)$ & $8.0(7.0,11.0)$ & $12.0(9.0,14.0)$ & $<0.001$ \\
\hline IL-6 (pg/ml) & $5.9(5.4,6.9)$ & $5.9(5.4,6.9)$ & $7.3(5.5,8.8)$ & $13.0(10.2,15.4)$ & $16.1(12.1,19.2)$ & $<0.001$ \\
\hline hs-CRP (mg/ml) & $1.9(1.1,2.1)$ & $2.1(1.3,3.1)$ & $3.1(2.2,4.3)$ & $5.6(5.3,6.4)$ & $6.6(5.4,7.3)$ & $<0.001$ \\
\hline
\end{tabular}

IQR - Interquartile Range U - Mann Whitney U test

TNF-a- Tumour Necrotic Factor-alpha; IL-6- Interleukin-6; hs-CRP- high sensitivity C-Reactive Protein; 
Table V: Correlation analyses of the various components of metabolic syndrome and markers of inflammation

\begin{tabular}{lllllll}
\hline Parameters & WC & SBP & DBP & FPG & TG & HDL-C \\
& $\boldsymbol{r}, \boldsymbol{p}$ & $\boldsymbol{r}, \boldsymbol{p}$ & $\boldsymbol{r}, \boldsymbol{p}$ & $\boldsymbol{r}, \boldsymbol{p}$ & $\boldsymbol{r}, \boldsymbol{p}$ & $\boldsymbol{r}, \boldsymbol{p}$ \\
\hline hs-CRP & $0.553,<0.001$ & $0.336,<0.001$ & $0.344,<0.001$ & $0.423,<0.001$ & $0.298,<0.001$ & $-0.257,<0.001$ \\
IL-6 & $0.390,<0.001$ & $0.407,<0.001$ & $0.437,<0.001$ & $0.341,<0.001$ & $0.277,<0.001$ & $-0.230,<0.001$ \\
TNF-a & $0.504,<0.001$ & $0.433,<0.001$ & $0.504,<0.001$ & $0.417,<0.001$ & $0.291,<0.001$ & $-0.287,<0.001$ \\
\hline
\end{tabular}

Correlation significance at 0.01 ( 2 tailed); $r$ - Correlation coefficient

TNF-a- Tumour Necrotic Factor-alpha; IL-6- Interleukin-6; hs-CRP- high sensitivity C-Reactive Protein. WC- Waist circumference; SBP- Systolic Blood Pressure; DBP- Diastolic Blood Pressure; FPG- Fasting Plasma Glucose; TG- Triglycerides; HDL-C- HighDensity Lipoprotein-Cholesterol

Table VI: Area Under the ROC curve and validity parameters of inflammatory biomarkers

\begin{tabular}{llll}
\hline Variables & AUC (95\%CI) & Sensitivity & Specificity \\
\hline Males & $0.989(1.000-1.000)$ & 0.966 & 1.000 \\
TNF-a (pg/ml) & $0.965(0.913-1.000)$ & 0.929 & 0.957 \\
IL-6 (pg/ml) & $0.932(0.872-0.993)$ & 0.964 & 0.848 \\
hs-CRP (mg/ml) & & \\
Females & $0.988(0.975-1.000)$ & 0.937 & 1.000 \\
TNF-a (pg/ml) & $0.986(0.973-1.000)$ & 0.958 & 0.948 \\
IL-6 (pg/ml) & $0.970(0.949-0.992)$ & 0.937 & 0.883 \\
hs-CRP (mg/ml) & & \\
\hline ROC - Receiver Operating Characteristic Curve; AUC - Area Under the Curve; & \\
TNF-a - Tumour Necrosis Factor-alpha; IL-6 - Interleukin-6; hs-CRP - High sensitivity C-Reactive Protein
\end{tabular}

However, studies have shown that levels of hsCRP, TNFa and IL-6 were correlated with increased FPG, triglyceride, blood pressure and decrease HDLc suggesting a correlation with increasing components of MetS. [25]

Contrary to the finding in the present study, a Mexican study demonstrated that there was no correlation between increased serum TNF-a levels with elevated serum triglyceride and cholesterol levels although low serum HDLc was correlated with serum TNFa. ${ }^{[26]}$ Also, an Indian study did not demonstrate a significant correlation between circulating TNFa or IL-6 with FPG and other lipid parameters. [27] The definite role of inflammation in the pathogenesis of MetS is not understood but it is hypothesized that bigger adipose tissue mass in obesity stimulates the release of TNFa and IL 6 which, consequently, is responsible for the production of CRP in the liver. [28] A Nigerian study which examined the role of inflammation on MetS reported a correlation between CRP and waist circumference. [15]

The present study assessed the ability of serum levels of hs-CRP, TNFa and IL-6 to discriminately identify MetS. All the biomarkers assessed in this study demonstrated good ability to discriminately identify MetS. It has been suggested that a panel of inflammatory markers will be useful in the diagnosis of MetS because of the complex interrelationship of these markers. Nevertheless, it was argued that a panel will guide the clinician in individualizing treatment and assessing the severity of the abnormality depending on the combination of aberrations. [14] It remains to be seen if such a suggestion will be beneficial in a resource-poor setting like Nigeria. Though the serum level of TNFa showed greater ability to discriminately identify MetS compared to the serum levels of IL- 6 and hs-CRP in the present study, further studies are needed to 
identify an inflammatory biomarker most predictive of MetS.

Authors' Contribution: AEN conceived the study and participated in data collection. AAO participated in data analysis and interpretation. All the authors participated in the drafting of the manuscript. All the authors approved the final version of the manuscript.

Conflict of interest: None declared.

Funding: Self-funded.

Publication History: Submitted 15 May 2020; Accepted 16 September 2020.

\section{References}

1. Alberti KG, Zimmet P, Shaw J. Metabolic syndrome-a new world-wide definition. A consensus statement from the International Diabetes Federation. Diabet Med 2006; 23: 469-480. doi:10.1111/j.1464-5491.2006.01858.

2. Rochlani Y, Pothineni NV, Kovelamudi S, Mehta JL. Metabolic syndrome: pathophysiology, management, and modulation by natural compounds. Ther Adv Cardiovasc Dis 2017; 11: 215-225. doi:10.1177/1753944717711379.

3. Dallmeier D, Larson MG, Vasan RS, Keaney Jr. FR, Fontes JD, Meigs JB, et al. Metabolic syndrome and inflammatory biomarkers: a community-based cross-sectional study at the Framingham Heart Study. Diabetol Metab Syndr 2012; $\quad 4$ : 28. https://doi.org/10.1186/1758-5996-4-28.

4. Selleck MJ, Senthil M, Wall NR. Making Meaningful Clinical Use of Biomarkers. Biomark Insights 2017; 12: 1-7. doi:10.1177/1177271917715236.

5. Sur G, Floca E, Kudor-Szabadi L, Sur ML, Sur D, Samasca G. The Relevance of Inflammatory Markers in Metabolic Syndrome. Maedica (Bucur) 2014; 9: 15-18.

6. Moreira PF, Dalboni MA, Cendoroglo M, Santos GM, Cendoroglo MS. Postprandial interleukin-6 response in elderly with abdominal obesity and metabolic syndrome. J Nutr Health Aging 2013; 17: 206210. doi:10.1007/s12603-012-0400.

7. Balasoiu M, Balasoiu AT, Stepan AE, Dinescu SN, Avramescu CS, Dumitrescu D. Proatherogenic adipocytokines levels in metabolic syndrome. Rom J Morphol Embryol. 2014; 55: 29-33.

8. Ghantous CM, Azrak Z, Hanache S, AbouKheir W, Zeidan A. Differential Role of Leptin and Adiponectin in cardiovascular system. Int J Endocrinol 2015; 2015:534320. https://doi.org/10.1155/2015/534320.

9. Pulkkinen L, Ukkola O, Kolehmainen M, Uusitupa M. Ghrelin in diabetes and metabolic syndrome. Int J Pept 2010, Article ID 248948. https://doi.org/10.1155/2010/248948.

10. Kodaman N, Aldrich MC, Sobota R, Asselbergs FW, Brown NJ, Moore JH, et al. Plasminogen Activator Inhibitor-1 and Diagnosis of the Metabolic Syndrome in a West African Population. J Am Heart Assoc 2016; 5: e003867. doi:10.1161/JAHA.116.003867.

11. Billiet L, Doaty S, Katz JD, Velasquez MT. Review of hyperuricemia as new marker for metabolic syndrome. ISRN Rheumatol 2014; 2014: 852954. doi:10.1155/2014/852954.

12. Pohjantahti-Maaroos $\mathrm{H}$, Palomaki $\mathrm{A}$, Kankkunen P, Laitinen R, Husgafvel S, Oksanen K. Circulating oxidized low-density lipoproteins and arterial elasticity: comparison between men with metabolic syndrome and physically active counterparts. Cardiovasc Diabetol 2010; 9: 41.doi:10.1186/1475-2840-9-41.

13. Martinelli N, Micaglio R, Consoli L, Guarini P, Grison E, Pizzolo F, et al. Low levels of serum paraoxonase activities are characteristic of metabolic syndrome and may influence the metabolic-syndrome- 
related risk of coronary artery disease. Exp Diabetes Res 2012; 2012: 231502. doi:10.1155/2012/231502.

14. Srikanthan K, Feyh A, Visweshwar H, Shapiro JI, Sodhi K. Systematic Review of Metabolic Syndrome Biomarkers: A Panel for Early Detection, Management, and Risk Stratification in the West Virginian Population. Int J Med Sci 2016; 13: 25-38. doi:10.7150/ijms.13800.

15. Udenze IC, Amadi EC, Awolola AN, Makwe CC, Ajie IO. Plasma levels of inflammatory cytokines in adult Nigerians with the metabolic syndrome. Niger Med J 2016; 57: 64-68. doi:10.4103/0300-1652.180569.

16. Ogbera AO, Azenabor A, Ogundahunsi OA, Ekun AO, Adejumo EN. Cytokines, Type 2 DM and the Metabolic Syndrome. Nig Qt J Hosp Med. 2013: 23: 318-322.

17. Adejumo EN, Ogundahunsi OA, Adejumo $\mathrm{AO}$, Sotunsa J, Jagun O. Prevalence of metabolic syndrome in a rural and urban community in South-west Nigeria using three different definitions. Int J Trop Dis Health 2017; 24: 1 e9. https://doi.org/10.9734/IJTDH/2017/33993

18. National Cholesterol Education Program (NCEP). Expert panel on detection and treatment of high blood cholesterol in adults. Third report of the national cholesterol education program (NCEP) expert panel on detection, evaluation, and treatment of high blood cholesterol in adults (Adult Treatment Panel III) Final Report. Circulation 2002; 106: $3143 \mathrm{e} 421$.

19. Reddy P, Lent-Schochet D, Ramakrishnan N, McLaughlin M, Jialal I. Metabolic syndrome is an inflammatory disorder: A conspiracy between adipose tissue and phagocytes. Clin Chim Acta 2019; 496: 35-44. doi:10.1016/j.cca.2019.06.019.
20. Le Lay S, Simard G, Martinez MC, Andriantsitohaina R. Oxidative stress and metabolic pathologies: from an adipocentric point of view. Oxid Med Cell Longev 2014; 2014:

908539. https://doi.org/10.1155/2014/908539.

21. Dallmeier D, Larson MG, Vasan RS, Keaney Jr JF, Fontes JD, Meigs JB, et al. Metabolic syndrome and inflammatory biomarkers: a community-based cross-sectional study at the Framingham Heart Study. Diabetol Metab Syndr 2012; 4: 28. doi:10.1186/1758-5996-428.

22. Phosat C, Panprathip P, Chumpathat N, Prangthip $\mathrm{P}, \quad$ Chantratita N, Soonthornworasisi N, et al. Elevated Creactive protein, interleukin 6 , tumor necrosis factor-alpha and glycemic load associated with Type 2 diabetes mellitus in rural Thais: a cross-sectional study. BMC Endocr Disord 2017; 17: 44. https://doi.org/10.1186/s12902017-0189-z.

23. Al-Shukaili A, AL-Ghafri S, Al-Marhoobi S, Al-Abri S, Al-Lawati J, Al-Maskari M. Analysis of inflammatory mediators in Type 2 diabetes patients. Int J Endocrinol 2013; 2013:

976810. http://dx.doi.org/10.1155/2013/976810.

24. Hossain M, Faruque MO, Kabir G, Hassan N, Sikdar D, Nahar Q, Ali L. Association of serum TNF-a and IL-6 with insulin secretion and insulin resistance in IFG and IGT subjects in a Bangladeshi population. Int J Diabetes Mellit 2010; 2:165-168. https://doi.org/10.1016/j.ijdm.2010.08.004.

25. Sharma, P. Inflammation and the metabolic syndrome. Indian J Clin Biochem 2011; 26: 317-318. doi: 10.1007/s12291-011-0175-6.

26. Esmaillzadeh A, Azadbakht L. Increased levels of inflammation among women with enlarged waist and elevated triglyceride concentrations. Ann Nutr Metab 2010; 57: 7784..https://doi.org/10.1159/000318588. 
27. Garcia VP, Rocha HNM, Sales ABK, Rocha NG, Lucas da Nóbrega AC. Sex Differences in High Sensitivity C-Reactive Protein in Subjects with Risk Factors of Metabolic Syndrome. Arq Bras Cardiol 2016; 106: 182187.

http:/ / dx.doi.org/10.5935/abc.20160027.

28. Lainampetch J, Panprathip P, Phosat C, Chumpathat
Soonthornworasiri $\mathrm{N}$, et al. Association of Tumor Necrosis Factor Alpha, Interleukin 6, and C-Reactive Protein with the Risk of Developing Type 2 Diabetes: A Retrospective Cohort Study of Rural Thais. J Diabetes Res 2019; Article

ID 9051929. https://doi.org/10.1155/2019/905 1929. 